management, the increasing sick leaves, level of work ability and occupational diseases, and

Discussion We are moving more and more towards an on demand economy, and the global supply chains disrupts and enhances national challenges. Newness require from the employees more diverse and constantly shifting qualifications and continuous updating and upgrading of skills. A higher level of own initiative and (self) management is needed - and to some extent there has been a transferring of risk assessment to the employee. The digitalisation and globalisation provides access to a broader labour force market, which bring more intense competition, and on-going automatization and robotics puts even more pressure on the work force to adapt. Even more, there is a blurring of the role and duties inbetween the employer and employees - and the physical work place is disappearing more and more.

Regulatory authorities need therefore to devise new methodologies and regimes for $\mathrm{OSH}$ regulation, with a holistic approach, and in close collaboration with all interested parties. It is by working together that we can really make a difference for all workers and in fact society as a whole.

\section{7 a FUTURE OF WORK, AND STRATEGIC RESEARCH PERSPECTIVES FROM THE NORDIC OCCUPATIONAL HEALTH RESEARCH INSTITUTES}

Päivi Mattila-Wiro, Wiking Husberg, Anne Vänskä, Timo Tuomi, Eyjolfur Sæmundsson, Yogindra Samant, Sture Bye, Glen Winzor, Nils Fallentin, Peter Green, Nina Stone, Magnus Falk.

\subsection{6/oemed-2018-ICOHabstracts.622}

Introduction Emerging risks, and constantly changing technologies which have an impact on the world of work require a continuously updated knowledgebase for policy makers and practitioners. The Nordic research institutes have a unique position in this effort where they attempt to provide strategic research inputs to the Future of Work initiative.

Methods Discussions in the group, Nordic research institutes inputs on strategic research perspectives looking in to the Future.

Results Perspectives Reports provides insights in to the strategic needs, with regard to Future of Work and occupational health.

Discussion The current perspectives report provided by the Nordic Future of Work Group, set up in 2016 as an initiative by the Director Generals of the Nordic Labour Inspectorates, has provided a basis upon which both the Nordic inspectorates and the Nordic institutes of occupational health have seen a need for building the knowledge base.

The broad mandate of the group includes the potential for recommending areas of research and research activities, and may as well include both continuous research within existing areas as well as potential new areas of research. Recommendations expected to come together with the research strategies of the Nordic institutes of occupational health in each Nordic country.

This presentation will provide some of the background for the strategic research perspectives from the Nordic countries aligned with the perspectives report and ongoing research on Future of Work.

\section{7b WORKING ANYTIME, ANYWHERE: THE EFFECTS ON THE WORLD OF WORK}

Oscar Vargas Llave, Jon Messenger. European Foundation for the Improvement of Living and Working Condition, Ireland

\subsection{6/oemed-2018-ICOHabstracts.623}

Introduction New information and communications technologies (ICT) have revolutionised everyday work and life in the 21 st century. They enable people to connect with friends and family - as well as with work colleagues and supervisors - at any point in time; however, they also facilitate the encroachment of paid work into the spaces and times normally reserved for personal life. The uncoupling of paid work from traditional office spaces has been a crucial factor in this development. Today's office work and, more broadly, knowledge work, is supported by the internet, and can be carried out from practically any location and at any time. This new spatial independence has transformed the role of technology in the work environment, offering both new opportunities and new challenges.

This report considers the impact of telework/ICT-mobile work (T/ICTM) on the world of work. T/ICTM can be defined as the use of ICT - such as smartphones, tablets, laptops and desktop computers - for the purposes of work outside the employer's premises. The report synthesises research carried out by Eurofound's network of European correspondents in 10 EU Member States - Belgium, Finland, France, Germany, Hungary, Italy, the Netherlands, Spain, Sweden and the UK - and by ILO country experts in Argentina, Brazil, India, Japan and the US. These contributors were asked to review and summarise the findings of data and research literature on the subject of T/ICTM in their respective countries.

The report classifies T/ICTM employees in relation to their place of work (home, office or another location) and the intensity and frequency of their work using ICT outside the employer's premises. The following groups were identified: regular home-based teleworkers; occasional T/ICTM workers, with mid-to-low mobility and frequency of work outside the employer's premises; and high mobile T/ICTM, with high frequency of working in various places, including working from home.

The extent of the adoption of T/ICTM across different countries, and its effects on working time, performance, work-life balance, and health and well-being are analysed using information from the national studies, supplemented by data from the sixth European Working Conditions Survey.

The report also reviews policy initiatives by governments, social partners and companies in relation to T/ICTM. The findings can contribute to the development of effective policies in the areas of digitalisation, fair working conditions and decent work in Europe and other regions of the world.

Methods A standard expert questionnaire on T/ICTM and its effects was jointly developed by Eurofound and the ILO in 2015. The questionnaire was used to structure and compile the data on T/ICTM available in each country analysed in this report. The breadth and depth of available data on T/ICTM vary substantially across the 15 countries observed. Data sources in all the national studies include large-scale surveys with individuals, while some include surveys with households and companies. Other information sources include research studies, in-depth interviews with experts and employers, white papers, 
laws and company policies on ICT-enabled work from outside the employer's premises.

The questionnaires for each country can be roughly divided into three groups, corresponding to the kind and quality of data sources used. Only limited pre-existing data on the topic could be made available in Brazil, Hungary, and India. Nationwide surveys on working from home and the use of ICT (generally as part of the labour force or working conditions surveys) in a more general sense were the main data source for the studies from Argentina, the US and the European countries. Surveys on T/ICTM in particular comprised the main data source for the report from Japan.

Statistics on T/ICTM were generated, to varying degrees, across these countries. What seems to fuel this variation is differing levels of interest in the topic among policymakers and public authorities. Policymakers and public authorities generally initiate and support research on T/ICTM in order to promote the adaptation of existing work arrangements and labour markets to the 'information age'. The actual adoption of $\mathrm{T} /$ ICTM among employers and employees seems to play a smaller role.

The information from Europe is complemented with data from the sixth wave (2015) of the European Working Conditions Survey (EWCS). The objectives of the EWCS are: (a) to measure working conditions across European countries on a harmonised basis; (b) to analyse relationships between different aspects of working conditions; (c) to identify groups at risks and issues of concern, as well as areas of progress; (d) to monitor trends over time; and (e) to contribute to European policy development, in particular on quality of work and employment issues. The survey included 43850 face-to-face interviews with workers - both employees and the selfemployed. Both descriptive and multivariate analysis have been developed to investigate the incidence of, and associations between, T/ICTM, working time, work-life balance and health and well-being (Eurofound, 2015a)6. In the analysis of the EWCS included in this report, only employees are included.

Results The incidence of T/ICTM is related not only to technological developments in different countries but also to existing economic structures and cultures of work. The countries analysed in this report with high shares of T/ICTM include Finland, Japan, the Netherlands, Sweden and the US.

Overall, the incidence of T/ICTM varies substantially, from $2 \%$ to $40 \%$ of employees, depending on the country, occupation, sector and the frequency with which employees engage in this type of work. Across the EU28, an average of about $17 \%$ of employees are engaged in T/ICTM. In most countries, larger proportions of workers carry out T/ICTM occasionally rather than on a regular basis. T/ICTM is more common among professionals and managers, but is also significant among clerical support and sales workers. In relation to gender, in general men are more likely to perform T/ICTM than women. However, women carry out more regular home-based telework than men. This suggests that country-specific gender roles and models of work and family life play a role in shaping T/ICTM.

Regarding the positive effects of T/ICTM, workers report a reduction in commuting time, greater working time autonomy leading to more flexibility in terms of working time organisation, better overall work-life balance, and higher productivity. Companies benefit from the improvement in work-life balance, which can lead to increased motivation and reduced turnover as well as enhanced productivity and efficiency, and from a reduction in the need for office space and associated costs. The disadvantages of T/ICTM are the tendency to lead to longer working hours, to create an overlap between paid work and personal life (work-home interference), and to result in work intensification. Home-based teleworkers seem to report better work-life balance, while 'high-mobile' workers are more at risk of negative health and well-being outcomes. Partial and occasional forms of T/ICTM appear to result in a more positive balance between the benefits and drawbacks. From a gender perspective, women doing T/ICTM tend to work shorter hours than men, and women seem to achieve slightly better work-life balance effects.

Discussion T/ICTM are highly ambiguous and perhaps even contradictory. Specifically, it appears that T/ICTM is not unequivocally advantageous compared to traditional office work at the employer's premises. Neither does it seem to result in mainly negative effects. On the positive side, workers report a reduction in commuting time, greater autonomy in working time organisation, better overall work-life balance and higher productivity. The disadvantages of T/ICTM with which workers seem to struggle the most are its tendency to extend working hours, create an overlap between paid work and personal life due to a blurring of work-life boundaries, and also lead to the intensification of work. It appears that many of these ambiguous or paradoxical effects have to do with the interactions among ICT use, the place of work in specific work environments and the characteristics of different occupations. Moreover, whether T/ICTM substitutes for work in the office, or instead supplements it, appears to be an important factor affecting whether the reported outcomes are positive or negative.

\section{7c IMPACT OF DIGITALISATION ON OCCUPATIONAL SAFETY AND HEALTH - AN EU-OSHA FORESIGHT}

${ }^{1}$ Emmanuelle Brun, ${ }^{1}$ Kate Palmer, ${ }^{1}$ Katalin Sas, ${ }^{1}$ Annick Starren, ${ }^{2}$ Xabier Irastorza*. ${ }^{1}$ Prevention and Research unit, EU-OSHA; ${ }^{2}$ European Agency for Safety and Health at Work, Spain

\subsection{6/oemed-2018-ICOHabstracts.624}

Introduction Digitalisation of the economy will fundamentally change the types of jobs available, forms of employment, where we work and how we work. This in turn may give rise to new and emerging OSH challenges that must be anticipated.

Methods EU-OSHA implemented a scenario-building 'foresight on new and emerging OSH risks associated with ICT by 2025', including on-line platforms, robotics and artificial intelligence, in two steps:

- Identification of key trends and drivers of change through horizon scanning and expert consultation;

- Development and testing of scenarios through an interactive process with stakeholders.

Follow-up expert review papers and study were commissioned on challenges highlighted in the foresight.

Results 92 Societal, Technological, Economic, Environmental and Political (STEEP) trends and drivers of change were identified and used to develop four scenarios on the future world of work and the new and emerging OSH risks associated with ICT. Each scenario presents different OSH challenges and opportunities. Expert review papers were prepared on crowdsourcing, robotics, 3-D printing, monitoring technologies and 